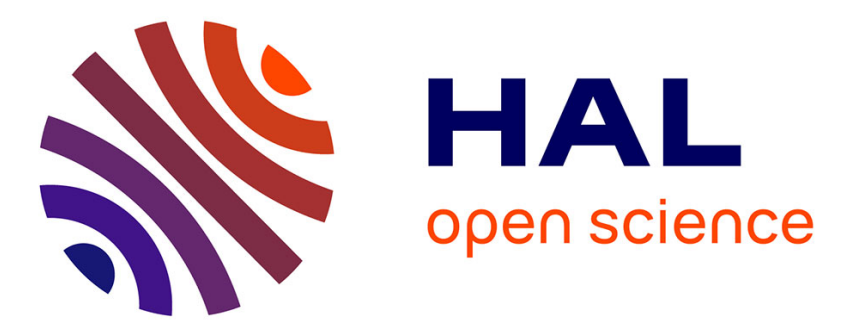

\title{
How can alien species inventories and interception data help us prevent insect invasions?
}

Marc Kenis, Wolfgang Rabitsch, Marie-Anne Auger-Rozenberg, Alain Roques

\section{To cite this version:}

Marc Kenis, Wolfgang Rabitsch, Marie-Anne Auger-Rozenberg, Alain Roques. How can alien species inventories and interception data help us prevent insect invasions?. Bulletin of Entomological Research, 2007, 97 (5), pp.489-502. 10.1017/S0007485307005184 . hal-02666220

\section{HAL Id: hal-02666220 \\ https://hal.inrae.fr/hal-02666220}

Submitted on 31 May 2020

HAL is a multi-disciplinary open access archive for the deposit and dissemination of scientific research documents, whether they are published or not. The documents may come from teaching and research institutions in France or abroad, or from public or private research centers.
L'archive ouverte pluridisciplinaire HAL, est destinée au dépôt et à la diffusion de documents scientifiques de niveau recherche, publiés ou non, émanant des établissements d'enseignement et de recherche français ou étrangers, des laboratoires publics ou privés. 


\section{Editorial Manager(tm) for Bulletin of Entomological Research Manuscript Draft}

Manuscript Number: BER-06-158R1

Title: How can alien species inventories and interception data help us prevent insect invasions?

Article Type: Full research paper

Keywords: invasive alien species; non-indigenous insects; pathways of introduction; economic impact; environmental impact; origin of alien species; feeding niche of alien species

Corresponding Author: Dr. Marc Kenis, Ph.D.

Corresponding Author's Institution: CABI Switzerland Centre

First Author: Marc Kenis

Order of Authors: Marc Kenis; Wolfgang Rabitsch; Marie-Anne Auger-Rozenberg; Alain Roques 
2 How can alien species inventories and interception data help us prevent insect

3 invasions?

4

5

6 Marc Kenis ${ }^{1}$, Wolfgang Rabitsch ${ }^{2,3}$, Marie-Anne Auger-Rozenberg ${ }^{4}$ and Alain Roques ${ }^{4}$

7

$8 \quad{ }^{1}$ CABI Bioscience Centre, 1, Rue des Grillons, 2800 Delémont, Switzerland.

$9 \quad{ }^{2}$ Austrian Federal Environment Agency Ltd. Dept. of Nature Conservation, Spittelauer Lände

105,1090 Vienna, Austria.

$11{ }^{3}$ Institute of Zoology, University of Vienna, Althanstrasse 14, A-1090 Vienna, Austria

$12{ }^{4}$ Institut National de la Recherche Agronomique (INRA), Station de Zoologie Forestière, Av.

13 de la pomme de pine, BP 20619, 45166 Olivet, France.

14

15

16

17 Correspondence author:

18 Marc Kenis, CABI Bioscience Switzerland Centre, 1, Rue des Grillons, 2800 Delémont,

19 Switzerland, m.kenis@cabi.org.

20

21 Running title: Alien species inventories and interception

22

23

24

25 
3 Information relevant to invasion processes and invasive alien insect species 4 management in Central Europe was extracted from two databases: a compilation of two 5 inventories of alien insects in Austria and Switzerland, and a list of interceptions of non6 indigenous plant pests in Europe gathered by the European and Mediterranean Plant 7 Protection Organisation (EPPO) for the period 1995-2004. For one third of the insects 8 established in Switzerland and Austria, the region of origin is unclear. Others come mainly 9 from North America, Asia and the Mediterranean region. Among the intercepted insects, 40\% were associated with commodities from Asia, 32\% from Europe and only 2\% from North

11 America. Sternorrhyncha, Coleoptera and Psocoptera were particularly well represented in the 12 alien fauna compared to the native fauna. In the interception database, Sternorrhyncha were 13 also well represented but Diptera accounted for the highest number of records. Sap feeders 14 and detritivores were the dominant feeding niches in the alien insect fauna. In contrast, 15 external defoliators, stem borers, gall makers, root feeders, predators and parasitoids were 16 underrepresented. Nearly $40 \%$ of the alien insects in Switzerland and Austria live only 17 indoors. Another $15 \%$ live outdoors but exclusively or predominantly on exotic plants. Less 18 than $20 \%$ are found mainly in "natural" environments. The majority of introductions of alien 19 insects in Europe are associated with the international trade in ornamental plants. An 20 economic impact was found for $40 \%$ of the alien insects in Switzerland and Austria whereas 21 none is known to have an ecological impact. The implications of these observations for 22 further studies and the management of alien species in Europe are discussed. 
1 Keywords: invasive alien species; non-indigenous insects; pathways of introduction;

2 economic impact; environmental impact; origin of alien species; feeding niche of alien 3 species

4

5

6 7

\section{Introduction}

Invasive alien species are recognized as one of the leading threats to biodiversity. The ways in which non-native species affect native species and ecosystems are numerous and usually irreversible (Parker et al., 1999). Non indigenous species also impose enormous costs on agriculture, forestry and human health (Pimentel et al., 2002b). Rapidly accelerating human trade, tourism, transport and travel over the past century have dramatically enhanced the spread of invasive species, allowing them to surmount geographic barriers. Since this tendency is likely to increase (Levine \& D'Antonio, 2003), national and international strategies are required to assess the full scope of the threat of invasive alien species, and deal with it effectively.

Insects represent the majority of living organisms and hence form a large part of the alien species problem. In many regions, such as North America, Australasia and South Africa, exotic insect pests are considered as important as native pests, if not more so (Pimentel, 2002b). Traditionally, problems have been less severe in Europe (Niemelä \& Mattson, 1996). However, in recent years several pests of economic importance have invaded Europe, inducing more interest in the issue of alien insects. For example, the western corn rootworm, Diabrotica virgifera virgifera LeConte is seriously threatening European maize production (Baufelt \& Enzian, 2005), and the horse-chestnut leaf miner, Cameraria ohridella Deschka 
1 and Dimic an insect of unknown origin, is causing much public concern because of its

2 spectacular damage on urban trees in Central Europe (Freise \& Heitland, 2004).

3 Management of alien species invasion requires a good knowledge of invasion

4 processes, i.e. pathways of introduction, establishment processes, species traits and habitat

5 characteristics that favour invasion (Williamson, 1996; Wittenberg \& Cock, 2001). It also

6 requires a precise assessment of economic and ecological hazards caused by the alien species

7 in order to improve risk assessments, define tolerance thresholds and evaluate the benefits of

8 control measures to be weighted against costs of control (Parker et al., 1999). Invasion

9 processes in invertebrates and pathogens are rather different from those observed in other

10 invasive organisms such as plants and vertebrates and, thus, require different strategies and

11 research priorities. Firstly, the introduction of invertebrates is usually accidental, biological

12 control agents being an exception (Causton et al., 2006). The introduction phase is rarely

13 observed and pathways of introduction are poorly known (National Research Council, 2002).

14 Secondly, when established in a new region, an insect quickly spreads to invade new regions

15 and habitats. In general, there is no obvious "lag phase", as is often seen in plant invasions

16 (e.g. Lonsdale, 1993) and when a lag phase is observed, it is usually of short duration

17 (Memmott et al., 2005; Drake \& Lodge, 2006). Consequently, an alien insect is usually

18 discovered when it is already firmly established, spreading and causing damage. An invasion

19 process is usually studied a posteriori, and management methods focus on the control of

20 already invasive, or damaging populations whereas, ideally, management efforts should be

21 directed to the first stages of the invasion processes by preventing introduction or develop

22 early eradication programmes (Puth \& Post, 2005).

23 Nevertheless, a posteriori studies of already established alien insects are useful to

24 assess which taxonomic or bioecological groups of alien species are better invaders or more

25 harmful to the economy or environment, and which ecosystems or habitats are more at risk 
1 (Mondor et al., 2006). Pathways and vectors of introduction can often be guessed from the

2 biology of the insect, supported by interception data from national phytosanitary services.

3 Such information allows the development or improvement of invasion risk assessment

4 methods for species, ecosystems or pathways (Wittenberg \& Cock, 2002).

5 Some European countries have recently established national lists of non-indigenous

6 organisms, including insects, as part of a national strategy to address invasive alien species

7 (e.g., Essl \& Rabitsch, 2002, for Austria; Geiter et al., 2002, for Germany; Wittenberg, 2005,

8 for Switzerland; Šefrová \& Laštůvka, 2005, for the Czech Republic; Hill et al., 2005, for

9 UK). The objectives of the present study were to extract, from a combination of the Swiss and

10 Austrian lists, information relevant to invasion processes and invasive alien species

11 management in Central Europe. In particular, we assessed insect species traits that correlate

12 with the ability to invade and determined which habitats have been particularly susceptible to

13 invasion. We also identified the most likely pathways or vectors for insect introductions and

14 compared the results with a dataset of interceptions of non-indigenous insects in Europe,

15 collected by national services of inspection and quarantine. Finally, we evaluated the actual

16 and potential economic and environmental hazards linked to insect invasions in Central

17 Europe, and propose recommendations for management and conservation.

\section{Material and Methods}

\section{Datasets}

A dataset of 341 non-indigenous insects of Austria and Switzerland has been built, 24 based on recent lists for Austria (Essl \& Rabitsch, 2002) and Switzerland (Kenis, 2005). The 25 criteria for including an insect species in the dataset were those used to build the Swiss list 
1 (Kenis, 2005), i.e. (1) it is believed to be non-indigenous in Austria and Switzerland; (2) there

2 is proof or at least a high probability that the insect has been introduced into Europe by

3 human activities (or into Austria and Switzerland for insects of European origin); (3) it is

4 permanently established in Austria and Switzerland, i.e. it is self-reproducing and would

5 maintain populations even without new introductions; this includes also insects that survive

6 only in heated environments such as houses, stores, greenhouses, compost heaps, etc. The

7 Austrian list (Essl \& Rabitsch, 2002) also includes non-established species and, thus, only the

8 insects that match the criteria mentioned above were incorporated in our dataset.

9 Archaeozoans, originally included in the Swiss list but not in the Austrian list, were included

10 in our analyses. A few non-indigenous insects have been added to the Austrian list since its

11 publication and data for some groups not treated therein (e.g. Diptera, Psocoptera, Anoplura)

12 were added from Fauna Europaea (2005).

13 Another dataset was built from data on the interceptions of non-indigenous plant pest

14 insects in Europe made by the national services of inspection and quarantine for the period

15 1995-2004. These data were regularly reported as notifications of non-compliance (detection

16 of regulated pests) by the European and Mediterranean Plant Protection Organisation (EPPO),

17 and were recently synthesized by two of the authors (Roques \& Auger-Rozenberg, 2006). It

18 does not include all insects intercepted but focuses primarily on alien insects that are on the

19 quarantine list of the EPPO or on insect groups that are potentially dangerous for plant health.

20 This database contains 6,743 interceptions of non-indigenous insects, from 28 European

21 countries, involving 13,558 individual specimens and 285 species identified to the species

22 level, of which 255 can be considered non-European. A sizable amount of intercepted alien

23 insects where identified at genus or family level only. From these, 19 genera were added to

24 our dataset because no species of these genera had been identified to the species level and, 
1 thus, these genera represent additional species. Hence, the list of intercepted insects comprises 2 a total of 274 species.

3 To test the hypothesis that the taxonomic distribution of the non-indigenous insect 4 fauna in Switzerland and Austria is similar to the native European fauna, we used Fauna 5 Europaea (2005) as reference for the insect fauna in Europe. To test the hypothesis that the 6 taxonomic distribution of the non-indigenous insect fauna of North America origin in 7 Switzerland and Austria is similar to the native North-American fauna, we used Simberloff 8 (1986).

9
Area of origin of the insects

\section{(1)}

The area of origin of each alien insect established in Austria or Switzerland was classified in one of the following regions: North America; Central and South America; Asia (except Mediterranean area, but including Continental Asian Turkey); Africa (except Mediterranean area); Eastern Europe; Southern Europe and Mediterranean region (including Northern Africa and Middle East); Pacific region (Australia, New Zealand and other Pacific islands); unknown. When the insect was thought to originate from two of these regions, the closest region to Central Europe was chosen. A similar classification was used for the interception data, but the origin was that of the commodity on which the insect was found rather than that of the origin of the species.

Feeding niche

Each insect of the dataset was categorized into one of the following feeding niches: external defoliators (including leaf rollers and webbers); sap feeders; leaf miners; gall makers; 
1 casebearers; wood borers; root borers/feeders; seed borers/feeders; stem borers (including

2 twigs, buds and flowerhead borers); fruit borers; parasitoids; predators; ectoparasites;

3 detritivores (including saprophages, coprophages and mycetophages); omnivores. Insects in

4 which larvae and adults occupy a different feeding niche were classified by the feeding niche

5 of the larval stage. When the larva passes through two feeding niches, we chose the feeding

6 niche in which it spends the longest time. Insects for which the biology is not known were

7 assigned to the "most-likely" feeding niche, i.e. that occupied by taxonomically closely-

8 related species.

9 An identical feeding niche classification was built for the European insects listed in

10 Fauna Europaea (2005), which comprises about 93,000 insect species. In this case, the

11 approximate proportion of each feeding niche was estimated by assigning each insect of the

12 list to the feeding niche encountered in its family or sub-family. For species-rich families and

13 sub-families showing two or more feeding niches, an approximate proportion of each feeding

14 niche was used, based on proportions calculated from regional or national checklists (e.g., for

15 diverse Coleoptera families and sub-families, we used Freude, et al., 1965-1983). We then

16 tested the hypothesis that the proportion of the feeding niches in the non-indigenous insect

17 fauna is similar to that of the native fauna.

Environment, host plant and EUNIS habitat stored products (including non-food products such as fabrics, but not wood products); domestic (i.e. living only in heated buildings, but not on stored products and not on living 24 plants in greenhouses); greenhouses; outdoors on indigenous host plant; outdoors on non25 indigenous host plant; outdoors on decaying matters (including compost heaps); aquatic; 
1 ectoparasite on vertebrates. Predators and parasitoids were categorized into the environment

2 of their main prey/hosts. Insects living in different environments were classified in the one

3 where they are most commonly found in Austria and Switzerland. Insects that are found

4 frequently on both indigenous and exotic plants were classified in the category "indigenous 5 host plant".

6 In addition, each insect was categorized into one of the major habitat classes of the 7 EUNIS classification (EEA 2005) present in Austria and Switzerland: C, inland surface

8 waters; D, mires bogs and fens; E, grasslands and lands dominated by forbs, mosses or 9 lichens; F, heathland, scrub and tundra; G, woodland, forest and other wooded land; H, inland unvegetated or sparsely vegetated habitats; I, regularly or recently cultivated agricultural,

11 horticultural and domestic habitats; J, constructed, industrial and other artificial habitats.

12 When an insect is known to occur in two or more habitat classes, the habitat in which it has 13 been most frequently reported was chosen.

14

\section{Pathways and vectors of introduction}

For each insect a pathway or vector of introduction into Europe (for non-European insects) or into Austria or Switzerland (for European insects) was allocated. Since, in most cases, the exact pathway is not known, the most likely vector was deduced by considering their preferred habitats, life style or food plant. The categories used were: host plant; wood material; stored products; biological control agents; host animal; others; multiple/unknown. Insects with two or more possible pathways or vectors were categorized as "multiple/unknown pathway". The proportion of these estimated pathways and vectors was compared with those of the interception dataset. The commodities associated with interceptions were classified into the following categories: ornamental trade (aquarium plants, 
1 bonsai trees, cut flowers, plants for planting, seeds), plant products for consumption (fruits,

2 stored products, vegetables), and wood and its derivates (wood, bark, wood packing material).

3

4

5

\section{Economic and ecological impacts}

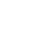

An insect was categorized as having an economic impact when we found at least one web page from Austrian, Switzerland or a neighbouring country describing damage and suggesting control methods. Similarly, an insect was considered as having an ecological impact when a publication or a web page from the same geographic region was found describing an environmental hazard associated with this insect.

\section{Results and Discussion}

\section{Comparison Between the Austrian and the Swiss databases}

Despite their proximity and similarity in size, geography, climate, environment and number of international ports of entry Switzerland and Austria have rather different alien insect faunas. Of the 341 species of the combined database, approximately one third of the species (35\%) are known only for Switzerland (90 species) or only for Austria (30 species). A significant proportion of species are recent invaders and their presence in the other country is expected for the near future. Table 1 shows a selection of alien insects that are presently recorded from one of the two countries only. Another factor that may explain the variation between the two countries is the difference in taxonomic expertise in the two countries. Some groups are better known in Switzerland (e.g. Diptera, Psocoptera, Sternorrhyncha), whereas others are particularly well covered in Austria (e.g. Lepidoptera, part of Coleoptera). 
3

4

For nearly one third of the alien insects in Austria and Switzerland, the region of origin is unclear. In some cases, such as the horse-chestnut leaf miner Cameraria ohridella, the insect appeared in Europe without having been described elsewhere and only data on its population ecology, parasitism and dispersal biology lead to the conclusion that it probably originated from another continent (Kenis et al., 2005). However, most insects classified as of "unknown origin" are species whose distribution is cosmopolitan and for which there is no agreement regarding their area of origin. This is particularly the case for the numerous stored product pests and some ectoparasites on animal pets that presently occur on most continents. The majority of the alien insects for which the area of origin is known came from Asia and North America (Fig. 1), two continents that include regions climatically and ecologically similar to Central Europe. A sizeable number of alien insects came from the Mediterranean region, probably on their host plants imported to Central Europe as crop planting material or products or as ornamentals. In recent years, Southern European species, e.g. moths and dragonflies, have been increasingly observed in Austria and Switzerland. Many of them are thought to migrate naturally, probably because of global warming, and are thus not included in the list (Kenis, 2005).

Among the alien insects intercepted by European phytosanitary services, many were found on commodities from Asia (39.8\%) and other European regions (32.0\%). Surprisingly few were found on commodities from North America (2.3\%) (Fig. 2), although North American insects account for $18 \%$ of the alien insect fauna in Switzerland and Austria (Fig. 1). This discrepancy between interception data and the origin of established insects may be explained by the climatic similarity between Europe and North America that allow smaller 
1 numbers of North American species and individuals to establish more easily in Europe than

2 tropical species. In addition, the interception data being based on recent records only (1995-

3 2004), the apparent difference with the alien fauna dataset may also reflect changes in foreign

4 trade in recent years, increasing exchange being made with more "exotic" regions,

5 particularly Asia for ornamental plants. Since the interception data concerned nearly

6 exclusively plant pests, it is not surprising to find many interception records on Asian

7 commodities. In their analysis of alien plant pests established in Great Britain, Smith et al.

8 (2005) also noted that Asia supplied a relatively high number of recent introductions.

9 Similarly, Haack $(2001,2006)$ noted that the most recent establishments and interceptions of

10 bark- and wood-boring Coleoptera in North America were or Asian origin. Furthermore, it

11 cannot be ruled out that the low occurrence of insects in North American imports may be due

12 to better sanitary practices in North America than in other regions.

\section{Taxonomic Groups}

Fig. 3 shows the taxonomic composition of the alien insects in Austria and Switzerland, which significantly differs from the composition of the native insect fauna in Europe (goodness of fit $\chi^{2}$ test; $\chi^{2}=568.50 ; \mathrm{P}<0.001$; the 12 smallest orders of Fig. 3 being pooled together to avoid low expected frequencies). Three insect orders and sub-orders are particularly overrepresented in the alien fauna compared to the native fauna: Coleoptera, Sternorrhyncha and Psocoptera. In contrast, Diptera and Hymenoptera are underrepresented. A comparison between the alien insects of North American origin in Switzerland and Austria and the native insect fauna in North America shows the same pattern (goodness of fit $\chi^{2}$ test; $\chi^{2}=111.69 ; \mathrm{P}<0.001 ;$ the 12 smallest orders of Fig. 4 being pooled together to avoid low expected frequencies), with American Sternorrhyncha having been more successful in 
1 invading Europe than other insect groups (Fig. 4). Alien insects in the USA show the same

2 pattern, except that alien Hymenoptera are proportionally much more abundant in North

3 America, partly because of the large number of exotic parasitoids introduced into North

4 America for biological control purposes (Simberloff 1986). Nevertheless, there are also much

5 more alien herbivorous Hymenoptera, particularly sawflies, in North America than in Europe

6 (Mattson et al., 1994) This overrepresentation of Coleoptera and Sternorrhyncha may be

7 explained by the fact that beetles are easily transported in or with stored products whereas

8 aphids, scale insects and whiteflies are often carried inconspicuously with their host plant.

9 The interception data show a somewhat different pattern (Fig. 5). Sternorrhyncha were

10 also frequently intercepted but, surprisingly, Diptera accounted for the highest number of

11 interceptions. Two third of these were agromyzid leaf miners and the remaining one third

12 were mainly fruit flies of the family Tephritidae. However, the number of species intercepted

13 per order led to a larger representation of Sternorrhyncha and Coleoptera, whose respective

14 proportions were similar to those observed in the established alien fauna. Moreover,

15 interception data are strongly biased by the fact that surveys concentrate on plant pests. For

16 example, Hymenoptera, the vast majority of which are parasitoids, predators or nectar/pollen

17 feeders, are hardly represented in the interception data. Nevertheless, many plant pests

18 intercepted by phytosanitary services probably contained hymenopteran parasitoids that have

19 the potential to become established and invasive.

\section{Feeding niche}

The proportion of feeding niches in the alien fauna is significantly different from that

24 of the European fauna (goodness of fit $\chi^{2}$ test, $\chi^{2}=366.57 ; \mathrm{P}<0.001$ ). Sap feeders and 25 detritivores are clearly the dominant feeding niches in the alien insect fauna of Austria and 
1 Switzerland. Their proportion in the alien fauna is much higher than in the European fauna

2 (Fig. 6). The majority of the sap feeders are Sternorrhyncha, followed by other Hemiptera and

3 Thysanoptera. Small sap feeders are unnoticeably carried from one region to another attached

4 to seedlings, cut flowers, vegetables, etc. Detritivores are well represented in the alien list

5 because many stored product pests belong to this category. Other guilds that are

6 proportionally more represented in the alien fauna than in the European fauna are wood

7 borers, fruit borers, seed feeders/borers and omnivores. In contrast, external defoliators, root

8 feeders/borers, stem borers, gall makers, predators and parasitoids seem to travel or establish

9 less successfully. The number of parasitoids is most probably underestimated in our dataset.

10 The frequency of parasitoids in insect faunas varies from $8.5 \%$ to $25 \%$ according to different

11 estimations (Godfray, 1994). Hence, in Austria and Switzerland only 11 alien parasitoid

12 species (3\% of the dataset) are recorded as probably established. All were released in Europe

13 as biological control agents. The absence of naturally introduced and established parasitoids

14 may suggest that these insects do not establish new populations easily. However, it almost

15 certainly also reflects their cryptic life-history and the taxonomic difficulties related to this

16 group. New indigenous parasitoid species are still described every year in Europe. Many

17 species are recorded from two or more continents, and it is probable that several of these

18 species invaded Europe from Asia or North America recently.

Environment, host plant and EUNIS habitat

Fig. 7 shows that nearly $40 \%$ of the alien insects in Austria and Switzerland live only indoors, in houses, stores, greenhouses, etc. Another 15\% live outdoors but exclusively or predominantly on exotic plants. Following the EUNIS classification, less than $20 \%$ of the alien insects live in a "natural environment", the majority of them occurring in regularly or 
1 recently cultivated agricultural, horticultural and domestic habitats, or in constructed,

2 industrial and other artificial habitats (Fig. 8). Among those insects that occur in "natural

3 environments", the vast majority are found in forest habitats, which includes plantations. It is

4 a common observation that simple, disturbed, human habitats are more readily invaded by

5 insects and other invaders than complex, undisturbed, natural habitats. Elton (1958) attributes

6 this phenomenon to the "biotic resistance", i.e. natural enemies and competitors that are more

7 prevalent in natural habitat than in disturbed habitats. Simberloff (1986) suggests two other,

8 more simple hypotheses to which we adhere. Firstly, disturbed, man-made habitats (i.e

9 agricultural and domestic habitats) are more important to humans and, thus, are studied more

10 carefully than natural habitats. As a result, new establishments are more likely to be detected.

11 Secondly, insects linked to human environments and activities (e.g. pests) are more likely to

12 be carried by human transports into a new region than insects living in natural areas. The

13 second hypothesis is confirmed by interception data that invariably contain far more

14 agricultural and domestic pests than insects linked exclusively to natural habitats. The first

15 hypothesis should be tested by extensive and specific surveys for alien species in natural 16 habitats.

Pathways and vectors of introduction

Among the 341 alien insects established in Austria and Switzerland, the exact pathway 21 of introduction is known with confidence for only the 12 biological control agents 22 deliberately released in Europe. However, for nearly $80 \%$ of the alien insect species, a likely 23 vector, usually a commodity, could be deduced or assumed based on their biology, plant or 24 animal host, etc. (Fig. 9). The main vectors of introduction were, in decreasing order, host 25 plants (accounting at least for nearly half of the introductions), stored products and wood 
1 material. Of those insects that were probably introduced with their host plant (wood

2 excluded), at least $40 \%$ undoubtedly came on ornamentals and $20 \%$ on vegetables and fruits.

3 From insects assumed to have arrived with wood material, about two-third are associated with

4 wood (logs, processed lumber or fresh wood packaging) and one-third with old wood material

5 (e.g. furniture). The relative proportion of vectors assessed from the establishment data and

6 the importance of the ornamental plant trade as pathway is confirmed by the interception data

7 (Table 2). Cut flowers, seedlings (nearly exclusively for ornamental purpose), bonsai trees,

8 seeds and aquarium plants represented $52.7 \%$ of the commodities on which insects were

9 intercepted. Nearly $30 \%$ of the insects were intercepted on cut flowers, which is about the

10 same proportion found on fresh food (vegetables and fruits). The relative efforts put on

11 inspection of these different commodities is not known, however, considering that food trade

12 is far more extensive than ornamental trade, one can assume that proportionally much more

13 alien insects were found on ornamentals than on vegetables and fruits. Interestingly, more

14 insects were intercepted on wood packaging (4.3\%) and bonsai trees $(4.2 \%)$ than on logs,

15 processed lumber and bark $(2.8 \%)\left(\chi^{2}=22.08, \mathrm{p}<0.01\right.$ and $\chi^{2}=19.40, \mathrm{p}<0.001$,

16 respectively). The origin of the commodity on which insects were intercepted strongly varies

17 with the type of commodity. Asia seems to be the major source for insects on bonsai trees

$18(96.7 \%)$ and wood packaging (76.9\%) whereas $47.9 \%$ of the insects intercepted on fresh

19 wood and bark came from Russia.

20

Economic and ecological impact

For 124 alien insects established in Austria or Switzerland (40\% of all species) data on economic damage are available from Austria, Switzerland or a neighbouring country. In contrast, the rate of native insects reaching pest status in temperate countries is probably 
1 much lower than 5\% (our estimates derived from numbers given in Pimentel, 2002; Pimentel

2 et al. 2002a; 2002b). Although alien insects represent only about $1 \%$ of the insect fauna in

3 Austria (Rabitsch \& Essl, 2006) and 1.7\% in continental United States (Simberloff, 1986), it

4 is usually estimated that between 30 and $45 \%$ of the insect pests in agriculture and forestry

5 worldwide are of alien origin (Pimentel et al., 2002a; 2002b). The higher rate of pest species

6 among non-indigenous faunas compared to indigenous faunas may be explained by three

7 factors that are not mutually exclusive. Firstly, alien insects causing economic damage are

8 more likely and more rapidly discovered than insects that are economically harmless. Thus, it

9 is very likely that many alien insects established in Austria or Switzerland in natural habitats

10 are yet to be discovered (Kenis, 2005). Secondly, insects are more likely to become pests as

11 introduced aliens than in their region of origin. Many alien insects having economic impact

12 are in fact of little, or of no importance in their region of origin, where they are controlled by

13 natural enemies and host resistance derived from co-evolutionary history (e.g. Löhr et al.,

14 1990; McClure \& Cheah, 1999). Thirdly, pests are more likely to invade new areas because

15 they are more abundant, their habitats are increasing in size and connectivity and they feed on

16 economically important plants or goods (Kenis, 2005). This is particularly the case with

17 stored product insects that have become pests in many regions and are regularly transported

18 with the commodities in which they live.

19 To our knowledge, no study has been carried out to investigate the ecological impact 20 of alien insect species in Austria and Switzerland, and only limited data are available for 21 Europe in general. A few alien insect species present Austria or Switzerland cause ecological 22 concerns in other regions. The ladybird Harmonia axyridis (Pallas), originally from eastern 23 Asia, is believed to out-compete and displace native aphidophagous species by predation and 24 competition for food in North America (Koch, 2003). This species has been recently recorded 25 in the wild in Europe, including Switzerland, where it is expected to cause similar damage 
1 (Klausnitzer, 2004; Majerus et al., 2006). The argentine ant, Linepithema humile (Mayr) is a

2 serious environmental pest in many regions in the world. It has been causing changes in 3 invertebrate and plant communities in the Mediterranean region by predation and 4 displacement of native species (Gómez \& Oliveras, 2003). It has been occasionally reported 5 from Switzerland where it reaches its ecological and climatic limit and will probably never 6 cause damage.

Species comparison between establishment and interception lists

The most frequently intercepted alien insect species are already established in Europe, if not in the wild, at least in greenhouses and other heated environments, e.g. Bemisia tabaci (Gennadius) (Hem.: Aleyrodidae, 1502 interceptions); Liriomyza huidobrensis (Blanchard) (Dipt.: Agromyzidae, 658); Helicoverpa armigera (Hübner) (Lep.: Noctuidae, 447); Frankliniella occidentalis (Pergande) (Thysan.: Thripidae, 222). However, several other species are very frequently intercepted and are not yet established in Europe, e.g. Tinocallis takachihoensis Higushi (Hem.: Aphidae, 62 records) or Asian Monochamus spp. (Col.: Cerambycidae, 65). On the other hand, many species that are already established in Europe have been very rarely or never intercepted. An interesting case is the recent introduction and spread of the western corn rootworm Diabrotica virgifera virgifera. A recent study showed that the different established populations in Europe originate from different populations (Miller et al., 2005), yet our interception list contains only one record for D. v. virgifera. Altogether, out of the 341 alien insect species in Switzerland and Austria, only $34(10.0 \%)$ were intercepted by phytosanitary services. On the other hand, only 34 out of the $274(12.4 \%)$ non-European alien species intercepted are known to be established in Switzerland or Austria. 
1 Similarly, only 42 intercepted species are found in the list of $381(11.0 \%)$ alien insects

2 established in the Czech Republic (Šefrová \& Laštůvka, 2005).

3 It is not clear why some species are frequently intercepted but never become

4 established, while others are rarely or never intercepted but become established. There are

5 probably numerous factors linked to the species biology and ecology (e.g. climate matching,

6 life cycle, host plant availability, taxonomic isolation of host plants, etc.) or to pathway

7 characteristics (e.g. phytosanitary regulations better implemented for some pathways). It must

8 be noted that more than half of the intercepted species are of tropical or subtropical origin,

9 which decreases the probability of establishment in the wild in most of Europe.

Another major constraint to investigate establishment successes is the lack of reliable, rigorous interception data. It may simply be that insects that are established but never 12 intercepted are often introduced but not intercepted on the right pathways at the right moment 13 using the right method. Work et al. (2005) estimated that even rigorous inspections probably 14 detected only $19 \%$ to $50 \%$ of the imported species, depending on the pathway. In addition, 15 interception surveys focus mainly on quarantine plant pests and targeted commodities (Haack, 16 2006). Insects belonging to economically unimportant groups are not searched for or not

\section{Implications for further studies and management strategies against alien insects}

Evaluation of species traits and habitat characteristics that make insects and habitats prone to invasion is a rewarding step towards understanding insect invasion processes as shown for plant or vertebrate invasions (Williamson, 1996; Alpert et al., 2000; Kolar \& 
1 Lodge, 2001). Such studies, unfortunately, are limited by lack of knowledge of the biology

2 and ecology of most insects, their distribution, especially in natural habitats, and their

3 pathways of introduction. Nevertheless, we were able to determine general patterns

4 characterising invading insects and invaded habitats. For example, our study clearly showed

5 that sap sucking Sternorrhyncha feeding on ornamental plants are more likely to be

6 introduced into a new region than, e.g., Lepidoptera defoliators or Coleoptera root feeders

7 living in natural habitats. However, it is not clear whether such generalizations are of much

8 help in building strategies for the prevention and management of invasive insects. Exceptions

9 are definitively too important to be neglected. For example, the two most damaging alien

10 insects in outdoor agriculture in Europe, the Colorado potato beetle, Leptinotarsa

11 decemlineata (Say), and the western corn rootworm, Diabrotica virgifera virgifera, are both

12 exceptional. Firstly, they are the only alien representatives of the species-rich family

13 Chrysomelidae, which does not seem to include successful invaders in general. Secondly,

14 they belong to two feeding niches, "external defoliators" and "root feeders", for which we

15 have found relatively few alien species. Thirdly, for neither of these two insects could clear

16 pathway of introduction be identified. Finally, they originate from Mexico and Central

17 America, regions that have not provided many other outdoor-living invaders in Europe.

18 Furthermore, many of the most damaging alien insects are not pests in their region of origin.

19 The two examples cited above were known before their introduction to Europe because they

20 had reached pest status when they invaded the USA and Canada. But other invasive species,

21 such as the horse-chestnut leaf miner Cameraria ohridella, the silver fir woolly aphid

22 Dreyfusia nordmannianae Eckstein and the eastern subterranean termite Reticulitermes

23 flavipes Kollar, were unknown before reaching Europe.

24 These examples unambiguously show that, with invasive alien insects, economic

25 and/or ecological threats arise from different geographic, taxonomic and ecological directions, 
1 as observed with other taxa (e.g. Levine et al., 2003). The unpredictability of insect

2 introductions and invasiveness, and the fact that the introduction of alien insects is usually

3 accidental and often detected only long after their establishment, put doubts on the usefulness

4 of species-based risk assessments for invasive alien insects (Simberloff, 2005). Standard

5 protocols for species-based risk assessment are most suitable for alien organisms introduced

6 deliberately, and for which an assessment is needed before the probable establishment in the

7 wild, e.g. ornamental plants, fishes, biological control agents, etc. (National Research

8 Council, 2002; Louda et al., 2003) In contrast, strategies against invasive alien insects should

9 focus on specific pathways and awareness building of the relevant authorities (Simberloff et

10 al., 2005). There are few examples of risk assessments for insects aimed at specific pathways.

11 Notable exceptions are the risk assessment procedures developed by US Department of

12 Agriculture to evaluate the risk of importing unprocessed larch from Russia and pine from

13 New Zealand and Mexico (e.g. Tkacz, 2002), but these were also calculated on a species-

14 based analysis by combining risks of introducing each particular species that may be

15 transported through these pathways. A better goal would be to define approaches to identify

16 and compare all key pathways and commodities, determine risks associated with each, and

17 sever or restrict the riskiest (Simberloff, 2005). However, until now, too little is known about

18 the pathways of introduction for alien insects to produce risk assessments for key pathways.

19 Interception data in Europe and elsewhere are usually strongly biased according to detection

20 priorities, which depend on pest or commodities of current concern (Haack, 2001, 2006). In

21 addition, there are large discrepancies among countries, ports of entries, etc. Furthermore,

22 insects are not always determined to species level. In the EPPO interception list, $69.8 \%$ and

$2388.1 \%$ of the insects were determined to species or genus level, respectively, because

24 interception efforts focused mainly on insects of quarantine significance. But in more

25 systematic interception surveys the percentage of insects identified to species level is usually 
1 much lower (e.g. 23\% in Work et al., 2005, 35\% in Haack, 2006). More importantly,

2 interception data only record positive data, whereas to fully analyse pathways and rates of

3 introduction, negative interceptions also need to be recorded. More studies should focus on

4 specific pathways, using a scientific approach that will produce statistically robust data, such

5 as that of Work et al. (2005). They used statistically-robust data collected by USDA APHIS at

6 US ports of entry as part of the Agricultural Quarantine Inspection Monitoring Protocol

7 (AQUIM, Venette et al., 2002) to estimate arrival rates of non indigenous insects via four

8 cargo pathways: air cargo, refrigerated and non-refrigerated maritime cargo and US-Mexico

9 border cargo. They determined the risks of invasion associated with each of these pathways

10 and were able to evaluate the effectiveness of current efforts to monitor arrival of alien

11 species. We strongly encourage the development of similar investigations on pathways of

12 introduction in Europe.

13 Despite important limits and bias, our analyses of pathways and vectors of

14 introduction were useful in identifying important patterns. In particular, they clearly showed

15 that host plants, especially ornamentals, are the most important vector for the introduction of

16 alien insects into Europe. More than half of the interceptions of alien insects in Europe were

17 made on cut flowers, seedlings, potted plants or bonsai trees. Our results on the most likely

18 pathways for introductions of established insects in Austria and Switzerland also emphasized

19 the role of ornamental plants as vectors. Similarly, Smith et al. (2005) found that all but one

20 of the significant invertebrate plant pests established in Great Britain after 1970 were on

21 ornamentals. Work et al. (2005) showed that $69 \%$ of the insect interceptions in air cargos

22 were on cut flowers whereas, in the US-Mexico border cargo, $75 \%$ of the insect interceptions

23 were associated with ornamental palms. Interestingly, the ornamental trade is also responsible

24 for the introduction and establishment of the majority of the most serious invasive plants in

25 Europe (Pyšek et al., 2002) and elsewhere (Reichard \& White, 2001). Similarly, many of the 
1 most invasive vertebrates in Europe, such as the grey squirrel Sciurus carolinensis and the

2 ruddy duck Oxyura jamaicensis, were initially introduced for aesthetic purposes (Wittenberg,

3 2005). Ornamental plants are by no means essential commodities for human welfare.

4 Therefore, their intercontinental trade should be more regulated. Instead, priority should be

5 given to locally grown indigenous plants. The importance of minor ornamental trades in the

6 introduction of invasive species is exemplified by the trade in bonsai trees. Nearly twice as

7 many pest insects are intercepted on bonsai trees as on timber. Insects intercepted on bonsai

8 trees include many aphids such as Cinara spp., Tinocallis viridis (Takahashi) and $T$.

9 takachihoensis and scales such as Saissetia neglecta DeLotto, but also long-horned beetles of

10 the genus Anoplophora. The bonsai trade is known to be responsible for the introduction of at

11 least one major tree pest in France, Italy and USA in recent years, the citrus longhorned beetle

12 Anoplophora chinensis (Förster) (Hérard et al., 2005; Haack, 2006).

13 This survey also showed that there is little information on the ecological impact of

14 invasive insects in Europe. In other parts of the world, quite a few invasive insects are known

15 to cause serious damage to the environment, but the impact is most often noticed when

16 "valuable" plant or animal species or entire ecosystems are affected, such as the hemlock and

17 balsam woolly adelgids Adelges tsugae and A. piceae destroying forest ecosystems in North

18 America, or the red fire ant Solenopsis invicta and the Formosan termite Coptotermes

19 formosanus causing structural damages to various ecosystems in Southern USA (Pimentel et

20 al., 2002a). There is a need for studies to properly assess the ecological impact of invasive

21 alien insects and take the appropriate conservation measures. In this paper, we showed that

22 only a minority of the alien insects in Central Europe live in natural habitats and,

23 consequently, have the potential to be detrimental to natural ecosystems. However, it is not

24 clear whether these data reflect a balanced view or just a lack of entomological and ecological

25 investigations in natural habitats compared to human habitats. 


\section{Acknowledgements}

3

4 We would like to thank F. Petter, A.Orlinski and A.S. Roy (EPPO Secretariat, Paris) for

5 access to the EPPO database on plant pest interceptions in Europe, Y. de Jong (Fauna

6 Europaea) for quantitative data on European insects, and M. Cock (CABI Bioscience

7 Switzerland Centre) and two anonymous reviewers for their comments on the manuscript.

8 This work was funded by the EU $6^{\text {th }}$ FWP projects ALARM (GOCE-CT-2003-506675) and

9 DAISIE (SSPI-CT-2003-511202).

\section{References}

12

Alpert, P., Bone, E. \& Holzapfel, C. (2000) Invasiveness, invasibility and the role of 14 environmental stress in the spread of non-native plants. Perspectives in Plant Ecology, Evolution and Systematics 3, 52-66.

16

Baufeld, P. \& Enzian, S. (2005) Maize growing, maize high-risk areas and potential yield losses due to western corn rootworm (Diabrotica virgifera virgifera) damage in selected European countries pp. 285-302 in Vidal, S., Kuhlmann, U. \& Edwards, C.R. (Eds.) Western Corn Rootworm: Ecology and Management. Wallingford, CAB International.

Causton, C.E., Peck, S.B., Sinclair, B.J., Roque-Albelo, L., Hodgson, C.J. \& Landry, B. (2006) Alien Insects: Threats and Implications for Conservation of Galápagos Islands. Annals of the Entomological Society of America 99, 121-143.

Drake, J.M. \& Lodge, D.M. (2006) Allee effects, propagule pressure and the probability of establishment: risk analysis for biological invasions. Biological Invasions 8, 365-375.

Elton, C.S. (1958) The Ecology of Invasions by Animals and Plants. London, Methuen.

Essl, F. \& Rabitsch, W. (eds.) (2002) Neobiota in Österreich. Wien, Umweltbundesamt. 
1 EEA (2005) EUNIS Habitat Classification. http://eunis.eea.eu.int/habitats.jsp. Cited 20 July

2

3 Freise, J.F. \& Heitland, W. (2004) Bionomics of the horse-chestnut leaf miner Cameraria ohridella Deschka and Dimic 1986, a pest on Aesculus hippocastanum in Europe (Insecta: Lepidoptera: Gracillariidae). Senckenbergiana Biologica 84, 1-20.

Freude, H., Harde, K.W. \& Lohse, G.A. (1965-1983) Die Käfer Mitteleuropas, Band 1-11. Krefeld, Germany, Goeke and Evers.

Fauna Europaea (2005). http://www.faunaeur.org. Cited 20 July 2006

Geiter, O., Homma, S. \& Kinzelbach, R. (2002) Bestandsaufnahme und Bewertung von Noezoen in Deutschland. Umweltforschungsplan des Bundesministeriums für Umwelt, Naturschutz und Reaktorsicherheit. Forschungsbericht 29689 901/'1 UBA-FB 000215.

Godfray, H.C.J. (1994) Parasitoids. Behavioral and Evolutionary Ecology. Princeton University Press, Princeton, USA.

Gómez, C. \& Oliveras, J. (2003) Can the Argentine ant (Linepithema humile Mayr) replace native ants in myrmecorchory? Acta Oecologica 24, 47-53.

Haack, R.A. (2001) Intercepted Scolytidae (Coleoptera) at U.S. ports of entry : 1985-2000. Integrated Pest Management Reviews 6, 253-282.

Haack, R.A. (2006) Exotic bark-and wood-boring Coleoptera in the United States : recent establishments and interceptions. Canadian Journal of Forest Research 36, 269-288.

Hérard, F., Jollivet, C. \& Reynaud, P. (2005) Gestion des foyers de capricornes asiatiques: en France, Autriche, Allemagne et Italie, l'éradication est lancée. Phytoma - La Défense des Végétaux 583, 22-26.

Hill, M., Baker, R., Broad, G., Chandler, P.J., Copp, G.H., Ellis, J., Jones, D., Hoyland, C., Laing, I., Longshaw, M., Moore, N., Parrot, D., Pearman, D., Preston, C., Smith, R.M. \& 
1 Waters, R. (2005) Audit of Non-Native Species in England. English Nature Research

2 Report 662, Northminister House, Peterborough, UK.

3 Kenis M (2005) Insects-Insecta pp. 131-212 in Wittenberg, R. (ed.) An inventory of alien 4 species and their threat to biodiversity and economy in Switzerland. CABI Bioscience

5 Switzerland Centre. Centre report to the Swiss Agency for Environment, Forests and $6 \quad$ Landscape.

7 Kenis, M., Tomov, R., Svatos, A., Schlinsog, P., Lopez Vaamonde, C., Heitland, W., 8 Grabenweger, G., Girardoz, S., Freise, J. \& Avtzis, N. (2005) The horse-chestnut leaf 9 miner in Europe. Prospects and Constraints for biological control pp. 77-90 in 10 Proceedings of the Second International Symposium on Biological Control of Arthropods, 11 Davos, Switzerland, 12-16 September 2005. Morgantown, WV, USA, Forest Health 12 Technology Enterprise Team.

13 Klausnitzer, B. (2004) Harmonia axyridis (Pallas, 1773) in Basel-Stadt (Coleoptera, 14 Coccinellidae). Mitteilungen der Entomologischen Gesellschaft Basel 54, 115-122.

15 Koch, R.L. (2003) The multicolored Asian lady beetle, Harmonia Axyridis: a review of its 16 biology, uses in biological control, and non-target impacts. Journal of Insect Science 3, 32 17 Available online: insectscience.org/3.32.

18 Kolar, C.S. \& Lodge, D.M. (2001) Progress in invasion biology: predicting invaders. Trends 19 in Ecology and Evolution 16, 199-204.

20 Levine, J.M. \& D’Antonio, C.M. (2003) Forecasting biological invasions with increasing 21 international trade. Conservation Biology 17, 322-326.

22 Levine, J.M., Vilà, M., D’Antonio, C.M., Dukes, J.S., Grigulis, K. \& Lavorel, S. (2003) 23 Mechanisms underlying the impact of exotic plant invasions. Philosophical Transactions 24 of the Royal Society of London 270, 775-781. 
1 Löhr, B., Varela, A.M. \& Santos, B. (1990) Exploration for natural enemies of the cassava 2 mealybug, Phenacoccus manihoti (Homoptera: Pseudococcidae), in South America for 3 the biological control of this introduced pest in Africa. Bulletin of Entomological $4 \quad$ Research 80, 417-421.

5 Lonsdale, W.M. (1993) Rates of spread on an invading species - Mimosa pigra in northern

7 Louda, S.M., Arnett, A.E., Rand, T.A. \& Russell, F.L. (2003) Invasiveness of some biological 8 control insects and adequacy of their ecological risk assessment and regulation. $9 \quad$ Conservation Biology 17, 322-326.

McClure, M.S. \& Cheah, C.A.S. (1999) Reshaping the ecology of invading populations of hemlock woolly adelgid, Adelges tsugae (Homoptera: Sdelgidae), in Eastern North America. Biological Invasions 1, 247-254.

Majerus, M.E.N., Strawson, V. \& Roy, H.E. (2006) The potential impacts of the arrival of the harlequin ladybird, Harmonia axyridis (Pallas) (Coleoptera: Coccinellidae), in Britain. Ecological Entomology 31, 207-215.

Mattson, W.J., Niemelä, P., Millers, I. \& Inguanzo, Y. (1994) Immigrant phytophagous insects on woody plants in the United States and Canada: an annotated list. General Technical Report NC-169. St. Paul (MN), US Department of Agriculture.

Memmott, J., Craze, P.G., Harman, H.M., Syrett, P. \& Fowler, S.V. (2005) The effect of propagule size on the invasion of an alien insect. Journal of Animal Ecology 74, 50-62.

Miller, N., Estoup, A., Toepfer, S., Bourguet, D., Lapchin, L., Derridj, S., Kim, K.S., Reynaud, P., Furlan, L. \& Guillemaud, T. (2005) Multiple transatlantic introductions of the western corn rootworm. Science 310, 992.

Mondor, E.B., Tremblay, M.N. \& Messing, R.H. (2006) Morphological and ecological traits promoting aphid colonization of the Hawaiian Islands. Biological Invasions (in press) 
1 National Research Council (United States) (2002) Predicting invasions of non-indigenous

2 plants and plant pests. Washington DC, National Academy Press.

3 Niemelä, P. \& Mattson, W.J. (1996) Invasion of North America Forest by European

4 phytophagous insects. Bioscience 46, 741-753.

5 Parker, I.M., Simberloff, D., Lonsdale, W.M., Goodell, K., Wonham, M., Kareiva, P.M.,

6 Williamson, M.H., Von Holle, B., Moyle, P.B., Byers, J.E. \& Goldwasser, L. (1999)

7 Impact: toward a framework for understanding the ecological effects of invaders.

$8 \quad$ Biological Invasions 1, 3-19.

9 Pimentel, D. (2002) Non-native invasive species of arthropods and plant pathogens in the

10 British Isles pp. 151-158 in Pimentel D (ed.) Biological Invasions. Economic and 11 Environmental costs of Alien Plants, Animal and Microbe Species. Boca Raton, USA, 12 CRC Press.

13 Pimentel, D., Lach, L., Zuniga, R. \& Morrison, D. (2002a) Environmental and economic costs

Pyšek, P., Sádlo, J. \& Mandák, B. (2002) Catalogue of alien plants of the Czech Republic. Preslia 74, 97-186.

Puth, L.M. \& Post, D.M. (2005) Studying invasion: have we missed the boat? Ecology Letters 25 
1 Rabitsch, W. \& Essl, F. (2006) Biological invasions in Austria: Patterns and case studies.

$2 \quad$ Biological Invasions 8, 295-308.

3 Reichard, S.H. \& White, P. (2001) Horticulture as a pathway of invasive plant introductions

$4 \quad$ in the United States. BioScience 51, 1003-113.

5 Roques, A. \& Auger-Rozenberg, M.A. (2006) Tentative analysis of the interceptions of

6 nonindigenous organisms in Europe during 1995-2004. EPPO Bulletin, in press.

7 Šefrová, H, \& Laštůvka, Z. (2005) Catalogue of alien animal species in the Czech Republic.

8 Acta Universitatis Agriculturae et Silviculturae Mendelianae Brunensis 53, 151-170.

9 Simberloff, D. (1986) Introduced insects: a biogeographic and systematic perspective pp. 3-26

10 in Mooney, H.A. \& Drake, J.A. (eds.) Ecology of Biological Invasions of North America

11 and Hawaii. New York, Springer-Verlag.

12 Simberloff, D. (2005) The politics of assessing risk for biological invasions: the USA as a 13 case study. Trends in Ecology and Evolution 20, 216-222.

14 Simberloff, D., Parker, I.M. \& Windle, P.N. (2005) Introduced species policy, management 15 and future research needs. Frontiers in Ecology and the Environment 3, 12-20.

16 Smith, R.M., Baker, R.H.A., Malumphy, C.P., Hockland S., Hammon, R.P., Ostojá17 Starzewski, J.C. \& Collins, D.W. (2005) Non-native invertebrate plant pests established 18 in Great Britain: an assessment of patterns and trends. BCPC Symposium Proceedings 81, $19 \quad 119-124$.

20 Tkacz, B.M. (2002) Pest risks associated with importing wood to the United States. Canadian 21 Journal of Plant Pathology 24, 111-116.

22 Venette, R.C., Moon, R.D. \& Hutchison, W.D. (2002) Strategies and statistics of sampling for 23 rare individuals. Annual Review of Entomology 47, 143-174.

24 Williamson, M. (1996) Biological invasions. London, Chapman and Hall. 
1 Wittenberg, R. (ed.) (2005) An Inventory of Alien Species and their Threat to Biodiversity and 2 Economy in Switzerland. CABI Bioscience Switzerland Centre. Centre report to the Swiss 3 Agency for Environment, Forests and Landscape.

4 Wittenberg, R. \& Cock, M.J.W. (2001) Invasive Alien Species: A Toolkit of Best Prevention 5 and management Practices. Wallingford, CAB International.

6 Work, T.T., McCullough, D.G., Cavey, J.F. \& Komsa, R. (2005) Arrival rate of 7 nonindigenous species into the United States through foreign trade. Biological Invasions $8 \quad 7,323-332$. 
Figure legends

Fig. 1. Proportional representation of the areas of origin of the 341 non-indigenous insects established in Austria and Switzerland

Fig. 2. Proportional representation of the origin of the commodities on which non-indigenous insects were intercepted by national phytosanitary services in Europe, 1995-2004.

Fig. 3. Proportions of insect orders and sub-orders in the 341 non-indigenous insect species in Austria and Switzerland (black bars) compared to the European insect fauna (source: Fauna Europaea, 2005) (white bars). Orders that were not treated in the Austrian and Swiss lists (e.g. all Apterygote, Mallophaga) were excluded from the analysis. "Others" include small orders $(<0.4 \%)$ for which no non.-indigenous species are known from Austria and Switzerland, i.e. Dermaptera, Mecoptera, Odonata, Phasmatodea, Strepsiptera.

Fig. 4. Proportions of insect orders and sub-orders in the 341 non-indigenous insect species in Austria and Switzerland originating from North America (black bars) compared to the North American insect fauna (Simberloff, 1986) (white bars). Orders that were not treated in the Swiss and Austrian lists (e.g. all Apterygote, Mallophaga) were excluded from the analysis. "Others" include small orders $(<0.4 \%)$ for which no non.-indigenous species are known from Switzerland and Austria, i.e. Dermaptera, Mecoptera, Phasmatodea, Strepsiptera.

Fig. 5. Proportion of insect orders and sub-orders in the non-indigenous insects intercepted by national phytosanitary services in Europe, 1995-2004. Black bars indicate the number of interceptions. White bars indicate the number of species intercepted.

Fig. 6. Proportional representation of the feeding niches of the 341 non-indigenous insects in Austria and Switzerland (black bars) and of the European insect fauna (white bars)

Fig. 7. Proportional representation of the environments and host plants of the 341 nonindigenous insects in Austria and Switzerland.

Fig. 8. Proportional representation of the main habitat classes (EUNIS classification) of the 341 non-indigenous insects in Austria and Switzerland. C, inland surface waters; D, mires bogs and fens; E, grasslands and lands dominated by forbs, mosses or lichens; F, heathland, scrub and tundra; G, woodland, forest and other wooded land; $H$, inland unvegetated or sparsely vegetated habitats; I, regularly or recently cultivated agricultural, horticultural and domestic habitats; J, constructed, industrial and other artificial habitats; ?, habitat unclear.

Fig. 9. Proportional representation of the most likely pathways and vectors of introduction for the 341 non-established insects in Austria and Switzerland. Fresh host plant refers to live or freshly cut host plants. 
Table 1. A selection of alien insect species recorded in only Switzerland or only Austria.

\begin{tabular}{ll}
\hline Recorded only in Switzerland & Recorded only in Austria \\
\hline Aedes albopictus (Skuse) [Dipt. Culicidae] & Anoplophora glabripennis (Motschulsky) [Col.: Cerambycidae] \\
Cacyreus marshalli (Butler) [Lep.: Lycaenidae] & Antheraea yamamai Guerin-Men. [Lep. Saturniidae] \\
Corythucha arcuata (Say) [Hem.: Tingidae] & Diuraphis noxia (Kurdjumov) [Hem.: Aphidae] \\
Orientus ishidae (Matsumura) [Hem.: Cicadellidae] & Lignyodes bischoffi (Blatchley) [Col.: Curculionidae] \\
Pulvinaria regalis Canard [Hem.: Coccidae] & Macropsis elaeagni Emeljanov [Hem.: Cicadellidae] \\
Rhagoletis completa Cresson [Dipt. Tephritidae] & Phyllonorycter issikii (Kumata) [Lep.: Gracillariidae] \\
Rodolia cardinalis (Mulsant) [Col. : Coccinellidae] & Sceliphron caementarium (Drury) [Hym.: Sphecidae] \\
\hline
\end{tabular}


Table 2: Relative importance of pathways and commodities associated with insect interceptions in Europe during 1995-2004.

\begin{tabular}{|c|c|c|c|}
\hline Pathway & Commodity & No. Interceptions & \%Interceptions \\
\hline \multirow[t]{5}{*}{ Ornamental trade } & Aquarium plants & 305 & 4.5 \\
\hline & Bonsai trees & 281 & 4.2 \\
\hline & Cut Flowers & 1939 & 28.8 \\
\hline & Plants for planting & 1003 & 14.9 \\
\hline & Seeds & 20 & 0.3 \\
\hline \multirow[t]{3}{*}{$\underline{\text { Food products }}$} & Fruits & 753 & 11.2 \\
\hline & Stored products & 610 & 9.0 \\
\hline & Vegetables & 1343 & 19.9 \\
\hline \multirow[t]{2}{*}{$\underline{\text { Wood and derivates }}$} & Wood/ Bark & 190 & 2.8 \\
\hline & Wood Package & 293 & 4.3 \\
\hline$\underline{\text { Miscellaneous }}$ & Unclear & 6 & 0.1 \\
\hline Total & & 6743 & 100 \\
\hline
\end{tabular}


Fig. 1

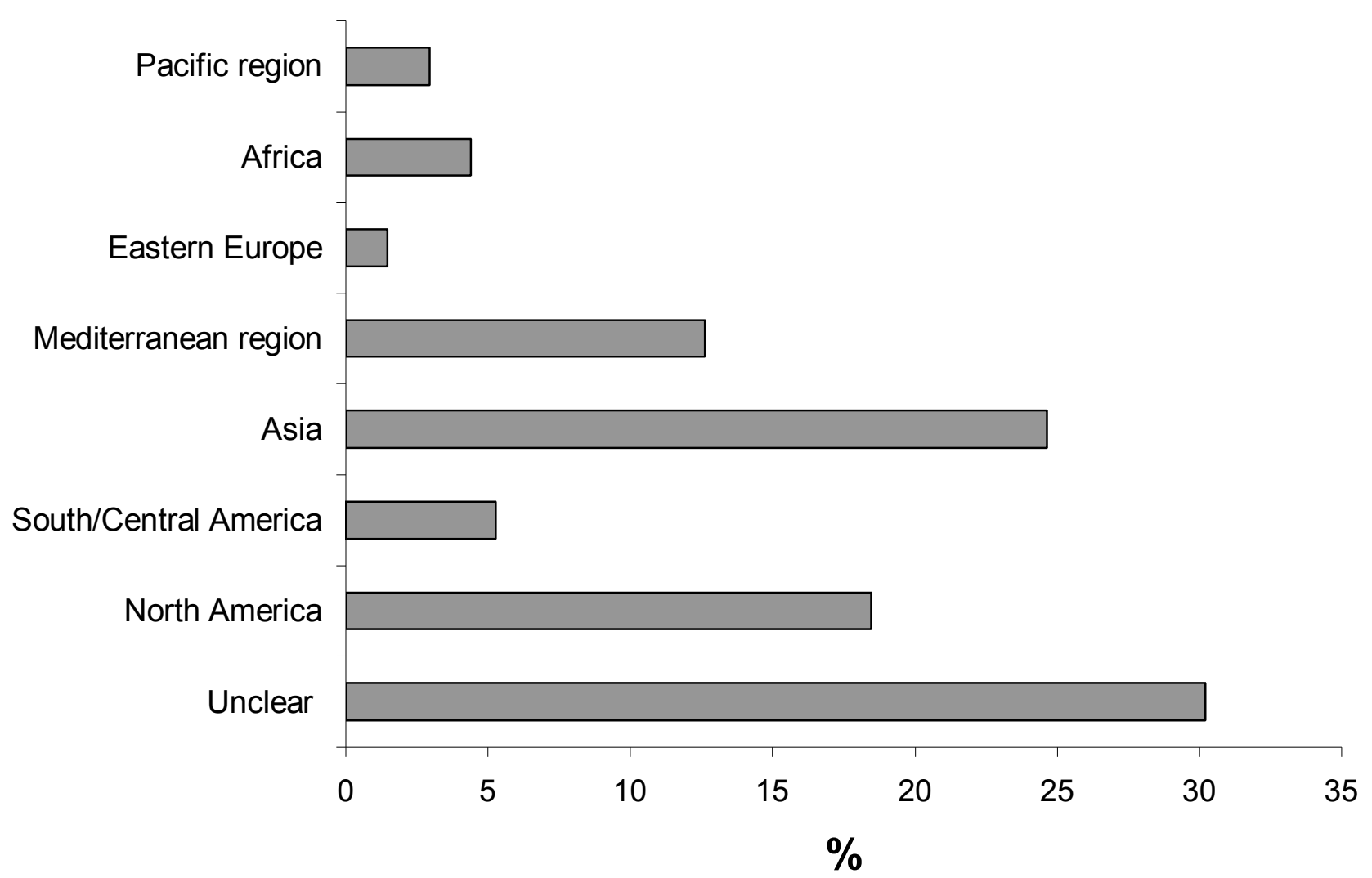


Fig. 2.

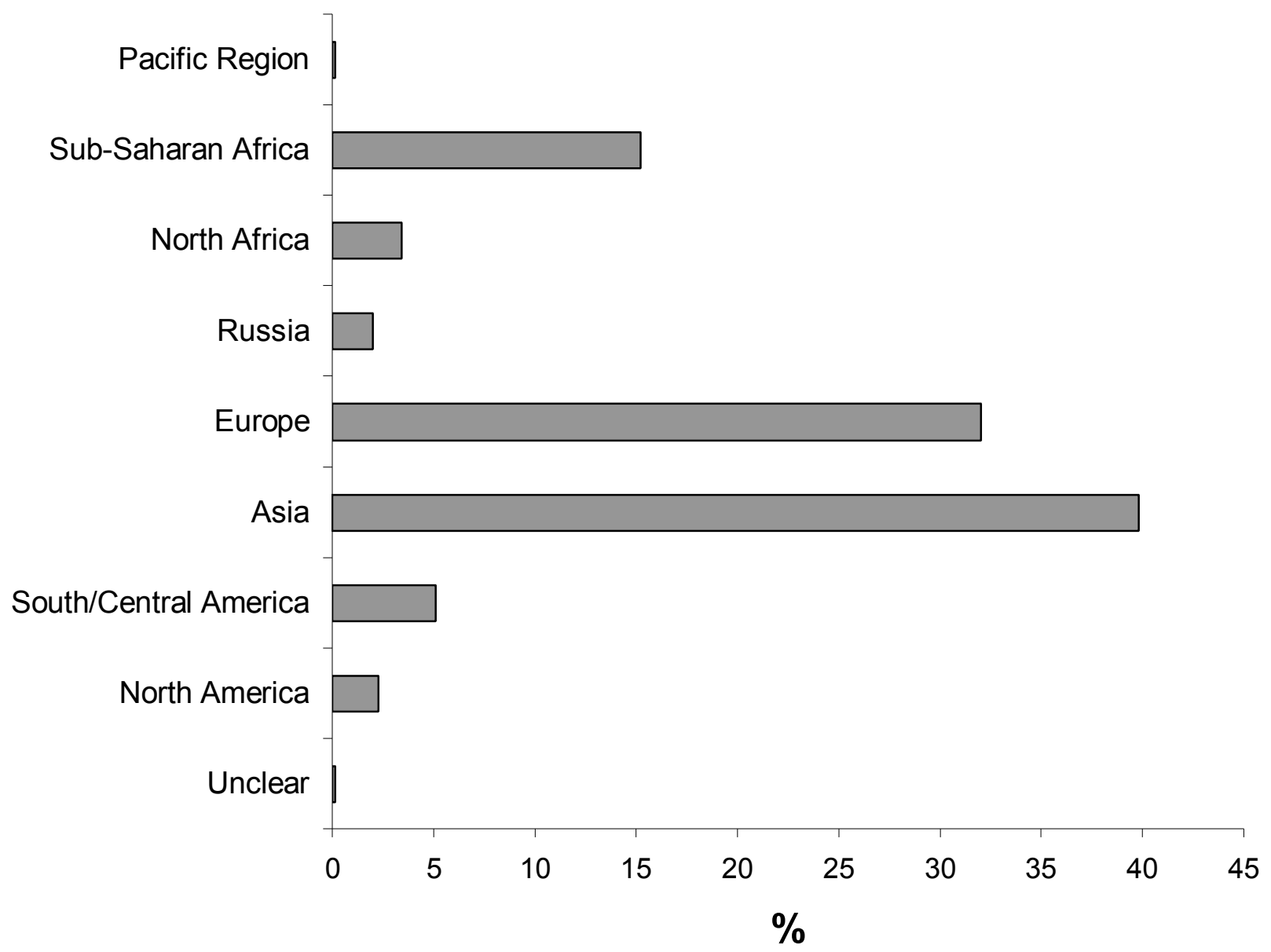


Fig. 3.
Others
Thysanoptera
Psocoptera
Plecoptera
Orthoptera
Odonata
Neuroptera s.I.
Isoptera

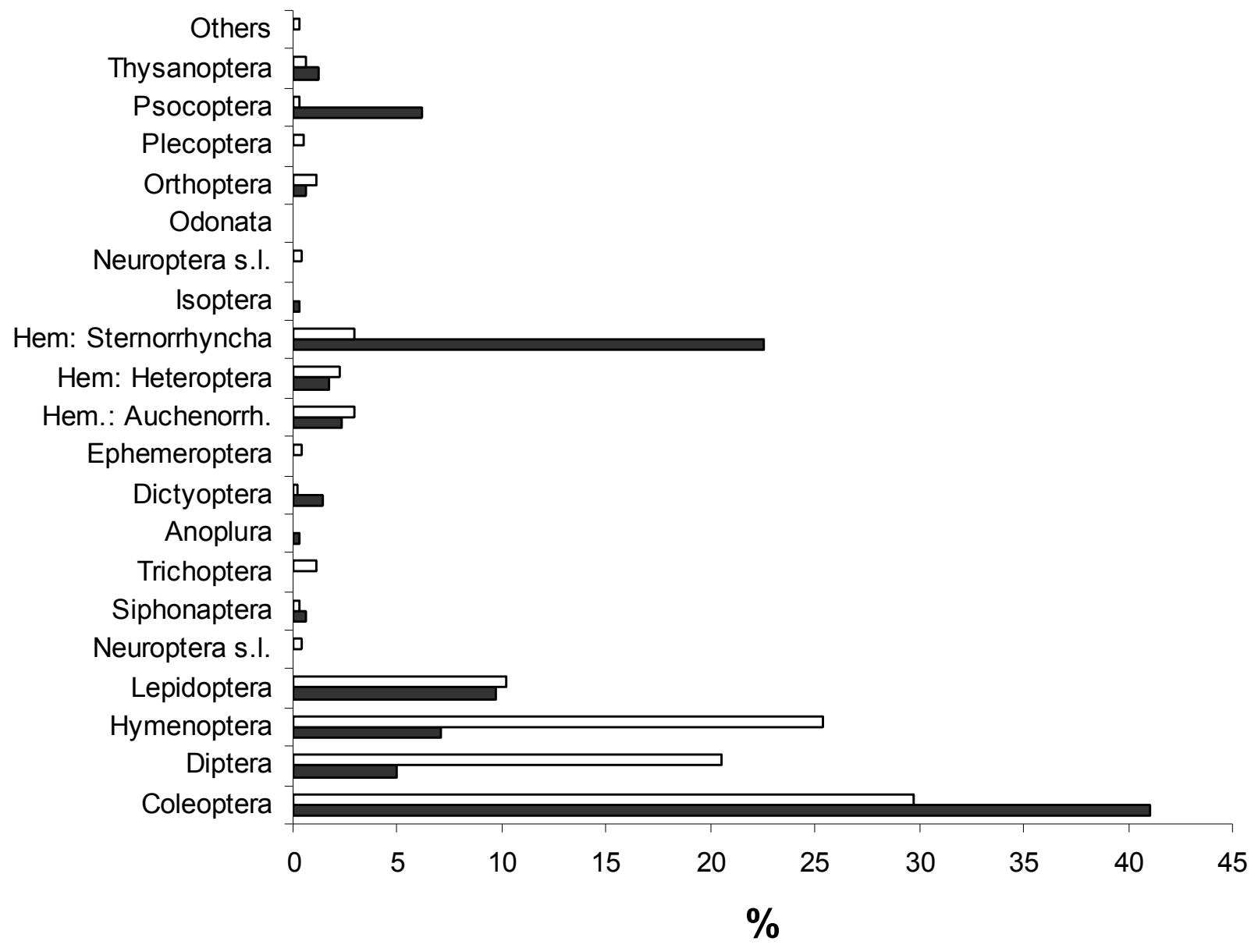

5


Fig. 4.

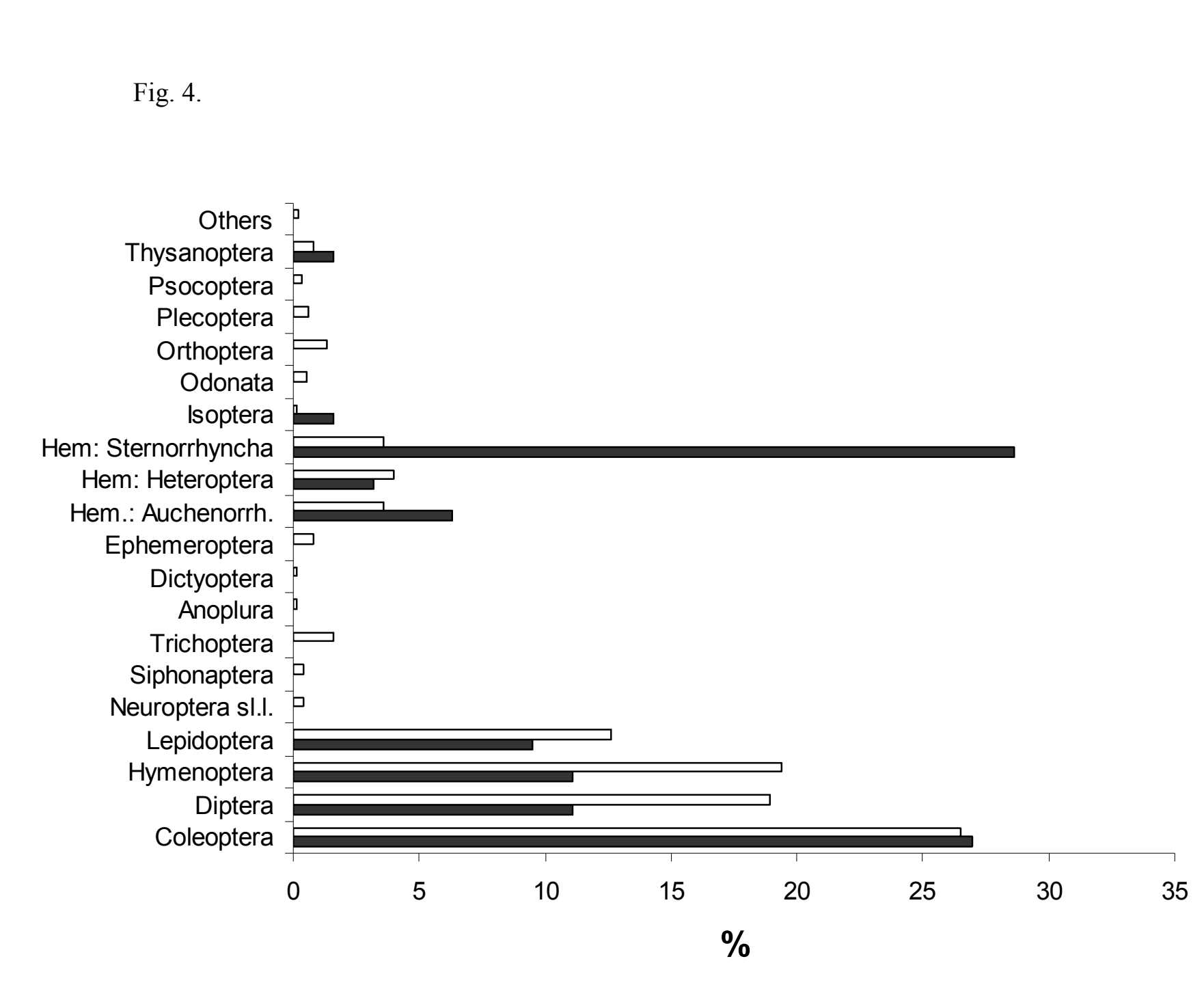

Fig. 4.

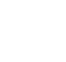


Fig. 5.

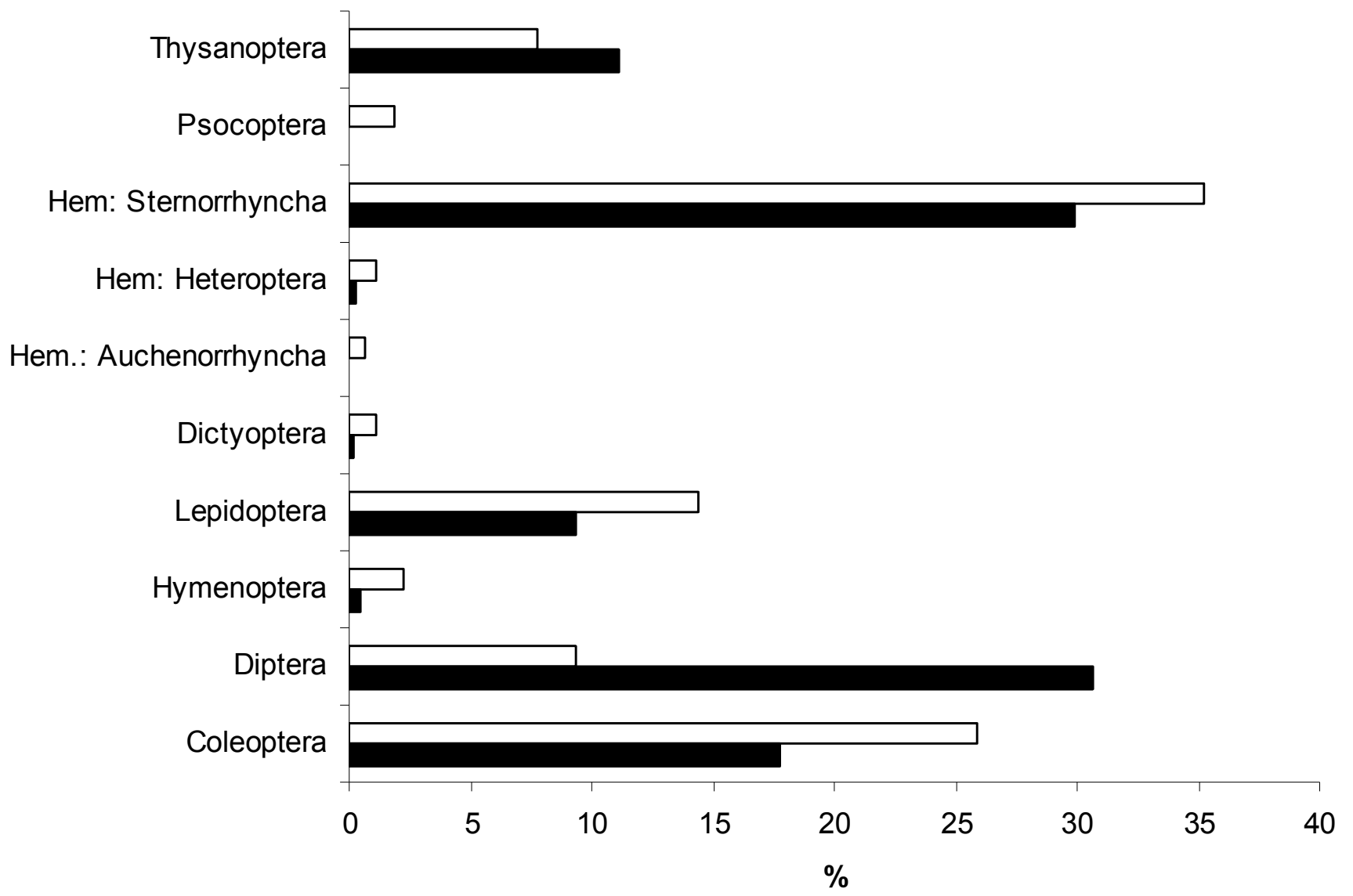


Fig. 6.

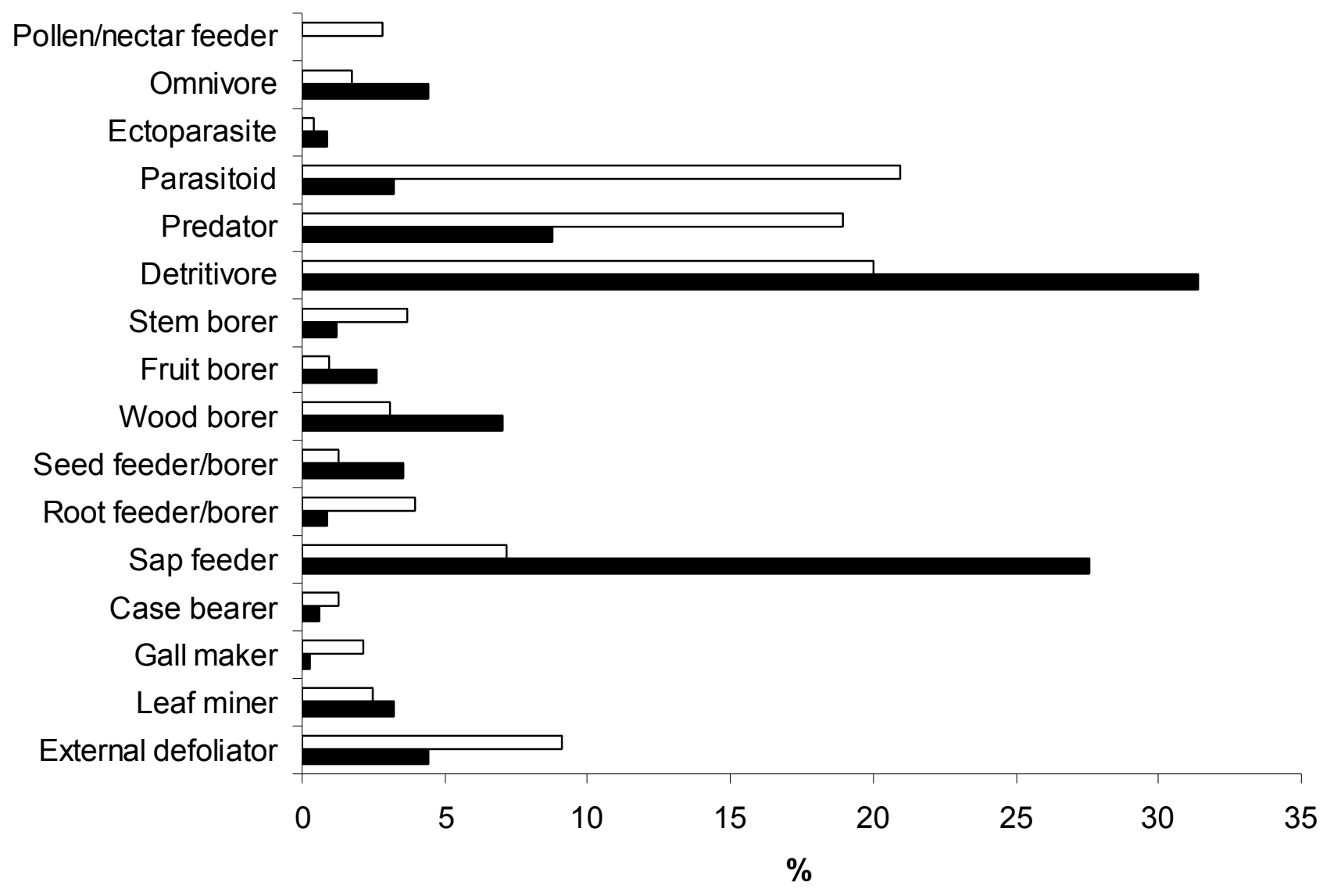


Fig. 7.

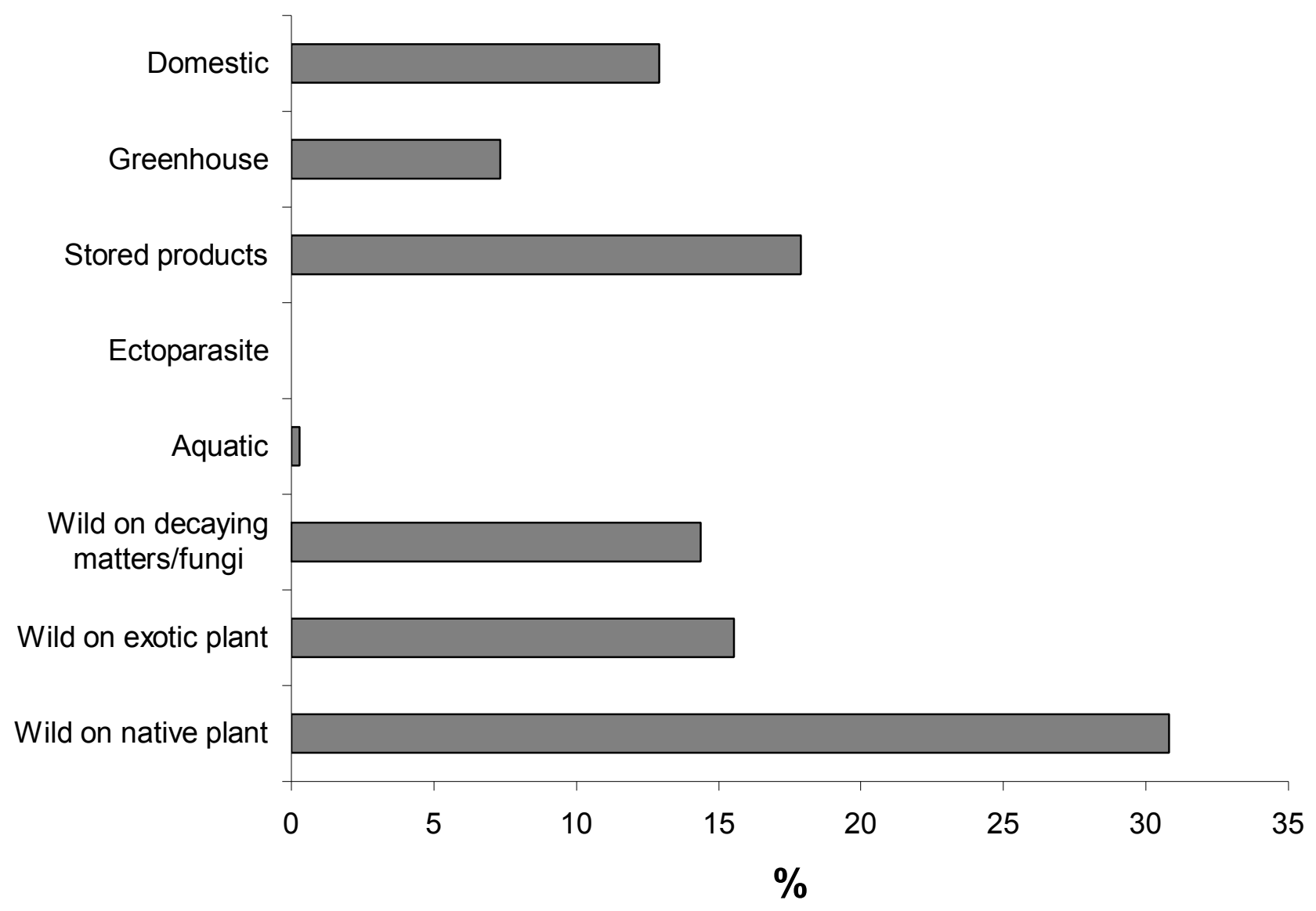


Fig. 8.

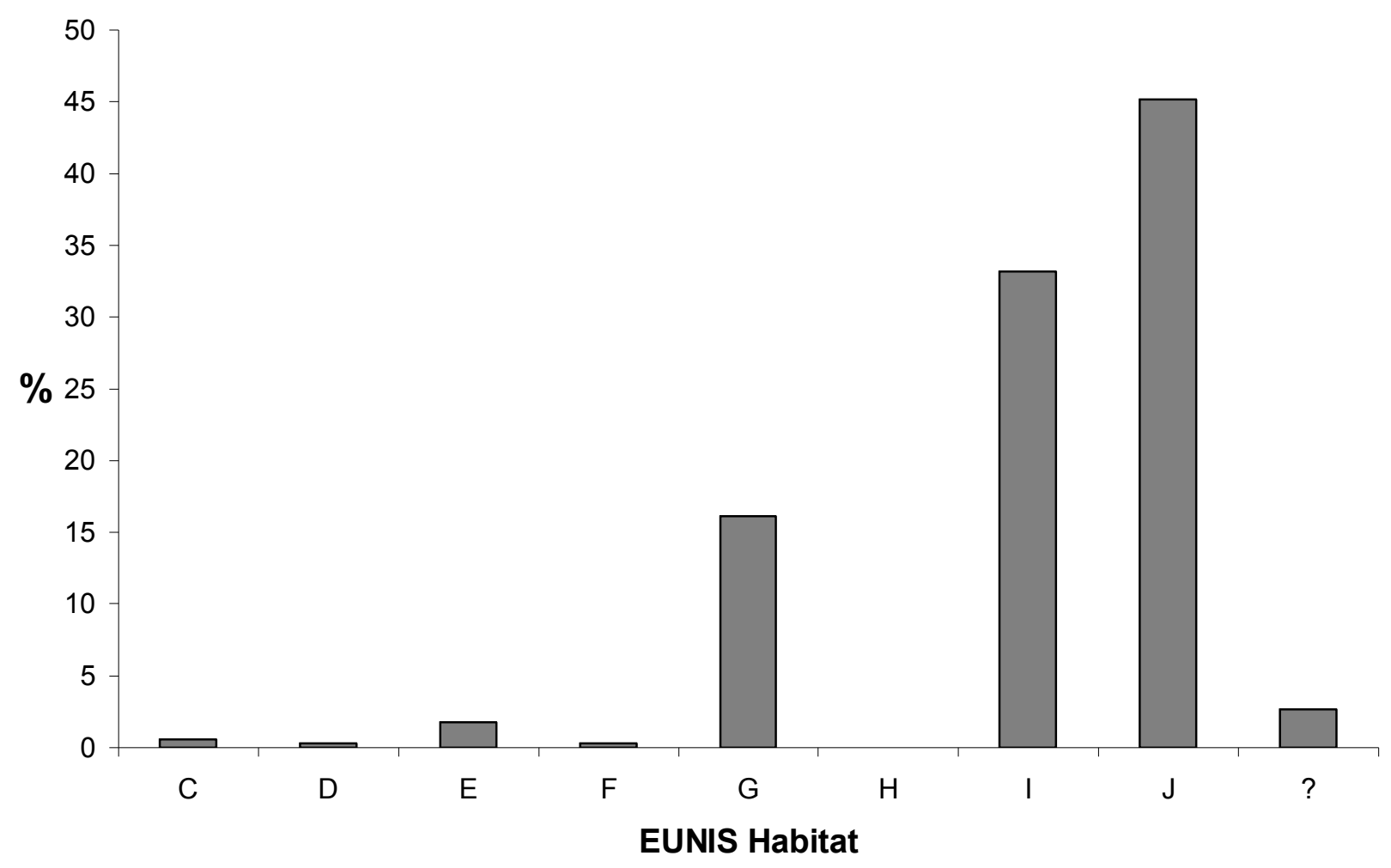


Fig. 9.

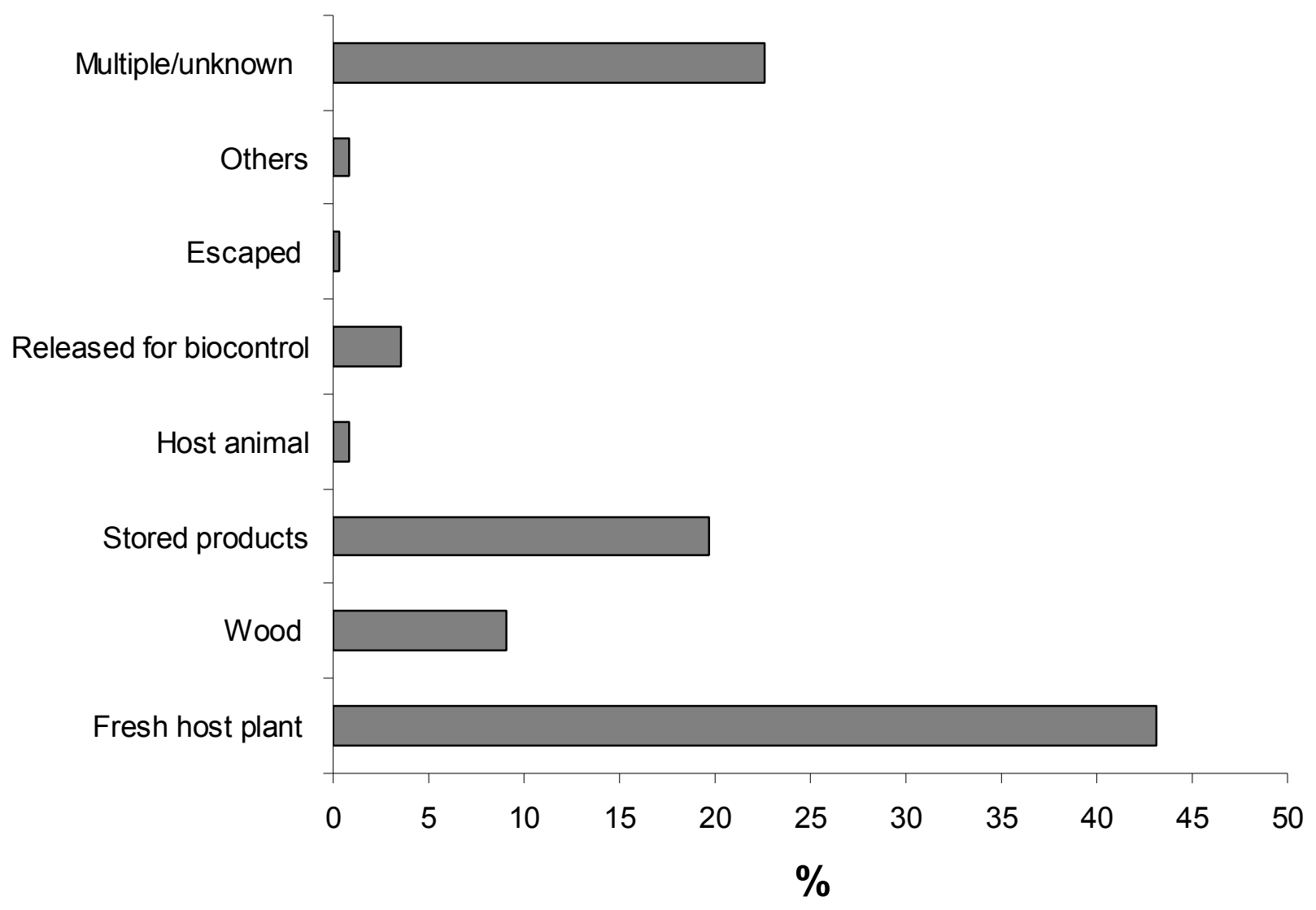




\section{${ }^{\star}$ Response to Referee Comments}

Response to the reviewers' comments - BER 06-158

First of all, we would like to thank the two reviewers for their excellent and detailed review. Most of their suggestions involved minor changes and have been incorporated. Details are given below. Regarding the statement on how this manuscript differs from Kenis (2005) and Roques and Auger-Rozenberg (in press), here it is:

There is no overlap with Kenis (2005), which is only an inventory with some comments on particular species, but no analysis as those presented in the BER paper. Roques and AugerRozenberg (in press) propose some rather similar analyses but only on the interception data (which is a minor part in the BER manuscript) and it covers all interceptions, whereas the BER paper analyses interceptions of insects only. Thus, we estimate that about $20 \%$ (e.g. 2 out of the 9 figures) of the results of the BER paper can be found, in a different form, in Roques and Auger-Rozenberg (in press). The vast majority of the analyses (based on insects established in Austria and Switzerland), is entirely new, as well as the whole discussion. We could have restricted the BER paper to the $80 \%$ entirely new data only and refer to Roques and Rozenberg (in press) for comparison, but the paper would have been much less readable, and we would have had to provide comparisons that constantly refer to a paper which is not easily available for the scientific community. In fact, Auger-Rozenberg (in press) originates from an EPPO meeting, for which EPPO required a short paper for their bulletin (kind of proceedings). This was requested when the manuscript of the BER paper was already half written. Please note that it was not our purpose to hide this small overlap between the two papers since we cite Roques and Auger-Rozenberg (in press) several times in the BER manuscript. We are of course ready to send PDFs of the two papers to the editor of BER, if necessary.

\section{Comments of Reviewer 1.}

1. We did not add "all alien insects" because there are a few orders which are not included in this database. It is clearly detailed in the Material and Method section, but we think it is not needed in the abstract, considering the size limit. We made the other suggested changes, but the abstract is now slightly over 250 words. If the editors think it is not acceptable, we are happy to delete the change regarding EPPO, which, according to us, is not essential.

2. We use now "horse-chestnut", which is the correct British spelling.

3. All done. Kenis (2005) has been (and still is) available on the web, but we have not mentioned this in the reference because the Federal Office for the Environmnent will remove it sooner or later and is presently printing much more copies for a larger distribution. We will have the exact reference of the new edition available for the proofs.

4. "Exotic insects" was replaced with Alien insects throughout the text. The classification of the areas of origin of the alien insects was clarified

5,6 \& 7 . Changes made

8. Difficult to describe the international ports-of-entry, but we added that they have similar numbers of ports-of-entry.

9. Changes made

10. We added the two references

11. True, but I think would be too long to discuss this. Furthermore, the example given by the referee concerns only wood-boring insects whereas the tendency towards invasions from

Asia concerns all groups.

12. Changes made

13. True, but we think that our sentence was sufficiently clear.

14. Changes made

15. Changes made

16. We have replaced "timber" by "logs and processed lumber". Regarding bark, this is the official terminology and classification used by EPPO and national plant protection organisations.

17. We now use the British word "ladybird"

18. BER is not very explicit regarding naming authorities of Latin names and Orders and Families. In the first version of the MS, we gave the naming authority at first mention in the main text but did not give authorities for species cited from published references. We gave Orders and Families only when we thought it was necessary. In the new version, we give 
authorities for al newly named insect, but give Order and Families only when it was part of the results.

19. Changes made

20. No. CPB was found in Europe before invading Asia.

21. We added Haack's references and some numbers

22. We did not mention the current international efforts to address the plant for planting pathway because nothing has been published yet. We added Haack 2006 as reference for Anoplophora chinensis

23. Changes made

24. Changes made

25. Pimentel et al, published the same paper in BioScience and in a book. We mention the book because it is the reference we used

26. Only two figures refer to interceptions, in which case we had already mentioned the date (but changed from 2005 to 2004). The other seven figures refer to lists of insects established in Austria and Switzerland. We added the number of alien species (341) in all captions but did not mention the cut-off date because it was slightly different in the two lists and it is already clearly defined in Material and Methods. Furthermore, since this is by no means a taxonomic paper, we felt it was not necessary to provide references to the names used for insect orders. Clearly, the taxonomy of most insect orders is debatable, but it was not the purpose of this paper.

27. Although most of the records listed in Table 1 are recent (after 1980), the dates of introduction are not always clear and there is a large variation between them. What we wanted to show is that, despite their very similar environments, not all alien insects are found in both countries. Therefore, we deleted the words "recently introduced" and also slightly modified the wording in the text. We did not footnote the abbreviations because we believe that readers of BER know that "Col." means Coleoptera and "Lep." Lepidoptera. We also deleted one species that is now found in both countries, and two for which the records were rather old.

28. Inserting the exact value of each bar provides indeed more precise data, but it makes the figures rather messy, especially when, as in our tables, there are quite a lot of bars per table. We tried but were not satisfied by the results. Before making the final decision, we looked into previous BER issues and did not see any figure where the exact value was added to the bars. Furthermore, some of the most important numbers are already mentioned in the text. Thus, we did not modify the figures, but could still do it, if the editors are of the same opinion as the reviewer. We did not really understand the question "what is the order of the bars in Fig 3 and 4?" If it refers to black and white bars, the signification is in the legend. Or does it refer to the order in which the insect orders are placed in the graph? We are not sure it really matters, but in case it does, we have now placed holometabolous insects at the bottom and hemimetabolous orders at the top, and placed the orders within these two groups in alphabetical order. Also the remark "in Fig 5, the order of clear bars and solid bars is reversed" is not clear, because Fig. 5 is not comparable to any of the other figures. It could mean that, in the other figures, black bars are placed below white bars. Thus, we have reversed black and white bars. We have modified the legend of Fig. 9 to explain what "fresh" means

\section{Reviewer 2.}

We did not separate herbivorous Hymenoptera and parasitoid/predatory Hymenoptera in the analyses. It is true that these groups are likely to behave differently in terms of invasion but (1) this is true for other orders (e.g. Coleoptera, Diptera, etc), then we should have done it for these groups as well; (2) augmenting the number of taxonomic groups would have made the figures less readable and the statistics more difficult to perform; (3) we investigated the effect of feeding niches in subsequent analyses; (4) we discussed the heterogeneity of Hymenoptera in the text

We followed the two other suggestions made by reviewer 2 and made the following changes according to his/her comments:

1. We have added a sentence on herbivorous Hymenoptera and the reference suggested by the reviewer. 
2. We have added taxonomic isolation of host plants as a possible factor explaining invasion success. 